\title{
A Two Step Synthesis Route of WC Nanopowders Ruqi Guan ${ }^{\mathrm{a}}$,Kailing $\mathrm{Hu}^{\mathrm{b}}$,Lihua Wang ${ }^{\mathrm{c}}$,Youjian Chen ${ }^{\mathrm{d}^{*}}$
}

${ }^{a}$ College of Chemistry and Materials Engineering, Wenzhou University, Wenzhou, Zhejiang 325027, PR China,

Crystal_guan@163.com

${ }^{b}$ College of Humanity, Wenzhou University, Wenzhou, Zhejiang 325027, PR China, 813493775@qq.com

'Shimadzu International Trading (Shanghai) Co., Ltd. Guangzhou, Guangdong ,510140 , PR China, wanglihua276@sina.com

${ }^{d}$ Zhejiang Jiahe plastic Co., Ltd. Jiaxing, Zhejiang 325027, PR China,

Chenyoujian1985@163.com

\section{ABSTRACT}

Here, a novel molten salt route to synthesize ceramic WC nanopowders was presented. Compared to the traditional synthesis procedures, this method is relatively low cost involving two-step synthesis route. In the argon atmosphere at 650 ${ }^{\circ} \mathrm{C}$, the powders were the mixed $\mathrm{WC}$ and $\mathrm{W}_{2} \mathrm{C}$ phases. These synthesized powders were transferred to a small crucible $(30 \mathrm{~mL})$ containing molten salt, which were put into a $500 \mathrm{~mL}$ crucible with some carbon powder in it as reducing atmosphere, followed by maintaining the reaction temperature at $1100{ }^{\circ} \mathrm{C}$ for $1 \mathrm{~h}$. The phase purity and composition were characterized by the powder X-ray diffractometer (XRD). It was found that $\mathrm{W}_{2} \mathrm{C}$ was transformed thoroughly into WC, which indicated the successful synthesis of WC powders using this method. The mechanism of the reaction process in molten salt has been discussed finally. The thermogravimetric analysis indicated that the as-prepared samples showed good thermal stability and oxidation resistance in high temperature. The methodology reported in this work was fundamentally important, which may find potential industrial applications.

\section{Keywords}

Ttungsten Carbide; Chemical Synthesis; Oxidation; X-ray Diffraction

\section{Council for Innovative Research}

Peer Review Research Publishing System

\section{Journal: Journal of Advances in Chemistry}

Vol. 6, No. 3

editor@cirworld.com

www.cirworld.com, member.cirworld.com 


\section{Introduction}

Due to the outstanding properties in high temperatures environment, carbides of transition metals have attracted considerable attention. Hexagonal tungsten carbide, among these carbides, is particularly important for industrial applications. It has some promising physical and chemical properties, such as high melting point $\left(2800{ }^{\circ} \mathrm{C}\right)$, high degree of hardness $(\mathrm{Hv}=22 \mathrm{GPa})$, high modulus of elasticity (696 GPa), low coefficient of thermal expansion $(5.2 \mu \mathrm{m} / \mathrm{m} / \mathrm{K})$, high fracture toughness (28 MPam1/2), good thermal and electrical conductivity, and good wear resistance over a wide range of temperatures [1]. Besides these, tungsten carbide has much higher compressive strength than some hard materials. Moreover, it has good oxidation resistance. Tungsten-base carbides perform very well up to about 1000 oF in oxidizing atmospheres and to $1500^{\circ} \mathrm{F}$ in non-oxidizing atmospheres.

Because of these properties, tungsten carbide is widely used for industrial applications, such as cutting materials, abrasive and anti-wear materials, aerospace materials, microelectronics industrials, abrasives and bearings materials, a hardness phase in cermets, extrusion and pressing dies and a cheaper alternative to diamond [2-8]. Besides, WC has proved to be an excellent catalyst in hydrogenation, methanation and ammonium reactions and it catalytic properties are usually superior to noble metal catalysts in selectivity, stability and resistance to poisoning [9-11]. Thus, it is considered as potential substitute for noble metal-based catalyst.

Traditionally, WC powders were commercially synthesized by the reaction of tungsten powders and carbon powders at the temperature from $1400{ }^{\circ} \mathrm{C}$ to $1600{ }^{\circ} \mathrm{C}$. However, the size of the product is of micro scale [12]. This synthesis route cannot satisfy the demands of nanometer-scale WC for modern industry. Hence, it is desired to develop new techniques to prepare uniform WC nanoparticles. Very fine WC powders are attractive for using in hard metal, because fine grained alloys exhibit higher hardness than coarser grained ones of the same composition at the same toughness level [13]. Recently, WC nanocrystalline has been synthesized at relative mild conditions. Kim et al. [14] synthesized nanostructured tungsten carbide powders by the chemical vapor condensation $(\mathrm{CVC})$ process using tungsten hexacarbonyl $\left(\mathrm{W}(\mathrm{CO})_{6}\right)$ precursor. Jin et al. [15] have synthesized nanometer WC powder at only $1000^{\circ} \mathrm{C}$ using ammonium metatungstate (AMT, $\left.\left(\mathrm{NH}_{4}\right)_{6} \mathrm{H}_{2} \mathrm{~W}_{12} \mathrm{O}_{40} \cdot \mathrm{XH}_{2} \mathrm{O}\right)$ and Glucose $\left(\mathrm{C}_{6} \mathrm{H}_{12} \mathrm{O}_{6}\right)$ by a new precursor method. Wei et al. [16] have synthesized WC-Co composite powder and densification by sinter-HIP. Cetinkaya et al. [17] have synthesized WC powder synthesis from prereduced $\mathrm{W}$ under pure and diluted $\mathrm{CH}_{4}$ atmospheres. Pallone et al. [18] have reported that $\mathrm{Al}_{2} \mathrm{O}_{3}-\mathrm{WC}$ composites have synthesized by high-energy reactive milling. Zawrah [19] has synthesized WC-Co nanocomposites by novel chemical method. Bolokang et al. [20] have synthesized WC powders by mechanical alloying. Essaki et al. [21] have prepared WC under microwave irradiation. Liu et al. [22] have adopted a novel rapid route for synthesizing WC-Co bulk by in situ reactions in spark plasma sintering. Zellner et al. [23] have synthesized phase-pure tungsten carbide (WC) and Ptmodified WC thin films by the physical vapor deposition (PVD) technique. Kumar et al. [24] have synthesized nano-WC by thermo-chemical reaction route and other relevant techniques [25-27].

In this paper, a two-step route to synthesize WC nanopowders has been developed, in which nanocrystalline $\mathrm{W}_{2} \mathrm{C}$ and WC powders were firstly synthesized by the reaction of metallic magnesium powders with $\mathrm{WO}_{3}$ and oxalic acid in an autoclave at $650{ }^{\circ} \mathrm{C}$. Furthermore, this method can prepare WC nanopowders by calcining the mixture of $\mathrm{W}_{2} \mathrm{C}$ and WC powders in molten salt.

\section{Experimental}

All the chemicals were analytical grade and used without further purification. $\mathrm{WO}_{3}, \mathrm{Mg}$ powders, $\mathrm{NaCl}$ and $\mathrm{C}_{2} \mathrm{H}_{2} \mathrm{O}_{4} \cdot 2 \mathrm{H}_{2} \mathrm{O}$ were raw materials and were purchased from Aladdin Chemical Reagents Co. LTD. Typically, $0.008 \mathrm{~mol} \mathrm{WO}_{3}(\mathrm{about} 1.86$ g), $0.01 \mathrm{~mol} \mathrm{Mg}$ powders (about $2.43 \mathrm{~g}$ ) and $0.008 \mathrm{~mol} \mathrm{C}_{2} \mathrm{H}_{2} \mathrm{O}_{4} \cdot 2 \mathrm{H}_{2} \mathrm{O}$ (about $1.02 \mathrm{~g}$ ) were put into a mortar orderly, followed by continuously grinding. Then the mixture was transferred to a stainless steel autoclave under argon atmosphere. The autoclave was heated at $650{ }^{\circ} \mathrm{C}$ for $8 \mathrm{~h}$, and then cooled to room temperature naturally. The product was collected and washed with dilute $\mathrm{HCl}$, distilled water, and absolute ethanol several times to remove all impurities and then dried in vacuum at $60{ }^{\circ} \mathrm{C}$ for $8 \mathrm{~h}$. Black powders were obtained.

The sample (prepared at $650{ }^{\circ} \mathrm{C}$ ) and $\mathrm{NaCl}$ were transferred to the $30 \mathrm{~mL}$ crucible. Then, the $30 \mathrm{~mL}$ crucible was put in a $500 \mathrm{~mL}$ crucible with some carbon powder in it as reducing atmosphere. The crucibles were heated at $1100{ }^{\circ} \mathrm{C}$ for $1 \mathrm{~h}$ and then cooled to room temperature naturally. The product was collected and washed with dilute distilled water, and absolute ethanol several times to remove all impurities and then dried in vacuum at $60{ }^{\circ} \mathrm{C}$ for $8 \mathrm{~h}$. Black powders were obtained.

The phase structure of the samples was analyzed by powder X-ray diffraction (XRD) on a Bruker D8 Advance X-ray powder diffractometer using $\mathrm{Cu} \mathrm{K- \alpha}$ radiation (wavelength $\lambda=1.54178 \AA$ ). The morphologies of the samples were characterized by a JEOL JSM-6700F scanning electron microscope. The thermogravimetric analysis was performed on a thermal analyzer (Model: Shimadzu DTG60AH) below $1000{ }^{\circ} \mathrm{C}$ in air at a rate of $10{ }^{\circ} \mathrm{C} \cdot \mathrm{min}-1$ to study its thermal stability and oxidation behavior.

\section{Results and discussion}

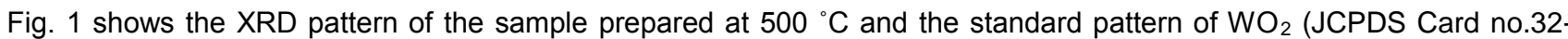
1393). There are some obvious diffraction peaks in the pattern in Fig.1(a). All these diffraction peaks at different $d$-space can be indexed to $\mathrm{WO}_{2}$. No evidences of impurities such as carbon, tungsten and tungsten trioxide, can be found in this pattern. The reaction process can be described as follows. Firstly, $\mathrm{C}_{2} \mathrm{H}_{2} \mathrm{O}_{4} \cdot 2 \mathrm{H}_{2} \mathrm{O}$ and metallic magnesium powders can react with other to produce amorphous carbon; there were no any peaks of carbon. Secondly, $\mathrm{WO}_{3}$ and metallic magnesium powders could react with each other to produce $\mathrm{WO}_{2}$ at $500{ }^{\circ} \mathrm{C}$ in the autoclave. 


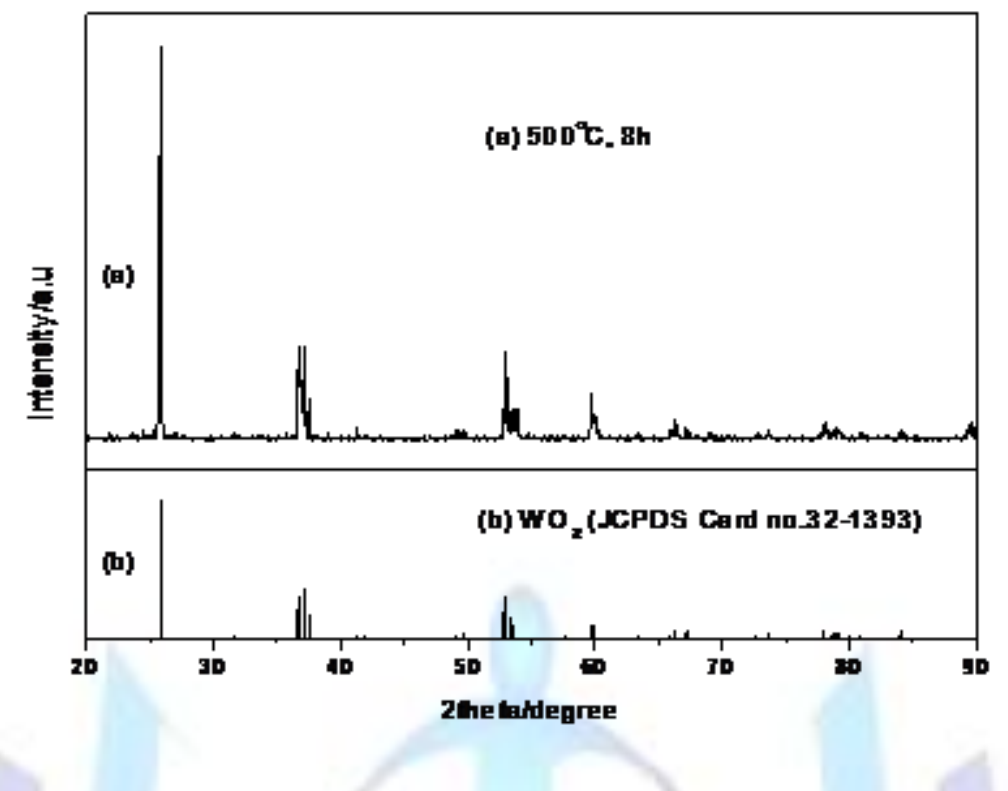

Fig. 1 XRD pattern of the sample prepared at $500{ }^{\circ} \mathrm{C}$ for $8 \mathrm{~h}$ and the standard pattern of $\mathrm{WO}_{2}\left(\mathrm{JCPDS}^{\mathrm{Card}}\right.$ no. $32-$ 1393)

Fig.2 shows the XRD patterns of the sample prepared at different reaction temperatures. The $\mathrm{WO}_{2}$ diffraction peaks cannot be found in these XRD patterns. The result can be obtained that $\mathrm{WO}_{3}$ can be reduced as tungsten powders by metallic magnesium powders at $550{ }^{\circ} \mathrm{C}$. It is well known that nascent tungsten and nascent carbon have high energy and chemical activation, which lead to chemical reactions in the autoclave during the synthesis route. Eqs. (1) and (2) indicate that the reactions of $\mathrm{W}$ and $\mathrm{C}$ are spontaneous in thermodynamic terms. Results on the preparation of WC powders by high-energy milling have been published [28]. However, it needs $120 \mathrm{~h}$ to obtain powders with nanometer-sized particles by milling. So the contamination should not be ignored.

$\mathrm{W}+\mathrm{C} \rightarrow \mathrm{WC} ; \Delta \mathrm{G} 298 \mathrm{~K}=-40.04 \mathrm{~kJ} / \mathrm{mol}$

$2 \mathrm{~W}+\mathrm{C} \rightarrow \mathrm{W}_{2} \mathrm{C} ; \Delta \mathrm{G} 298 \mathrm{~K}=-26.36 \mathrm{~kJ} / \mathrm{mol}$

According to Fig. 2(a), it is obvious that there was trace W2C and WC. When the reaction temperature is $550{ }^{\circ} \mathrm{C}$, the reaction did take place. But there was some unreacted W. As the temperature increasing to $600{ }^{\circ} \mathrm{C}$, the intensity of diffraction peaks of $\mathrm{W}$ was weaker and the intensity of diffraction peaks of $\mathrm{W}_{2} \mathrm{C}$ and $\mathrm{WC}$ become stronger. The pattern (b) shows that this sample was composed of $\mathrm{W}_{2} \mathrm{C}$ and $\mathrm{WC}$ and little of $\mathrm{W}$. The reaction rate of Eqs. 1 and 2 will be enhanced at increasing the reaction temperature, however, the reaction did not complete thoroughly. XRD patterns of the product prepared at $650{ }^{\circ} \mathrm{C}$ for $8 \mathrm{~h}$ are shown in Fig. 2c. The patterns of powders synthesized at $650{ }^{\circ} \mathrm{C}$ show that the diffraction peaks of $\mathrm{W}$ powders almost disappear, and there were obvious trace of $\mathrm{W}_{2} \mathrm{C}$ and $\mathrm{WC}$. Compared to pattern $\mathrm{b}$ in the Fig.2, we can conclude that the amount of WC increased while $\mathrm{W}_{2} \mathrm{C}$ decreased as the reaction temperature increasing. So, we can obtain some results from the Fig.2. First, it can be suggested that $W$ and $C$ could react to produce $W_{2} C$ and $W C$ at $550{ }^{\circ} \mathrm{C}$. Second, as the reaction temperature increasing, the reaction keeps going on in accordance with the Eq. (1) and (2). Third, meanwhile, there might be a reaction as Eq. (3).

$$
\mathrm{C}+\mathrm{W}_{2} \mathrm{C} \rightarrow 2 \mathrm{WC}
$$

That's the reason why the amount of $W_{2} C$ decreased while the amount of WC increased according to the reaction temperature. Fourth, if the reaction temperature rises to a certain value, we can conclude that the $\mathrm{W}_{2} \mathrm{C}$ will transform to WC gradually. 


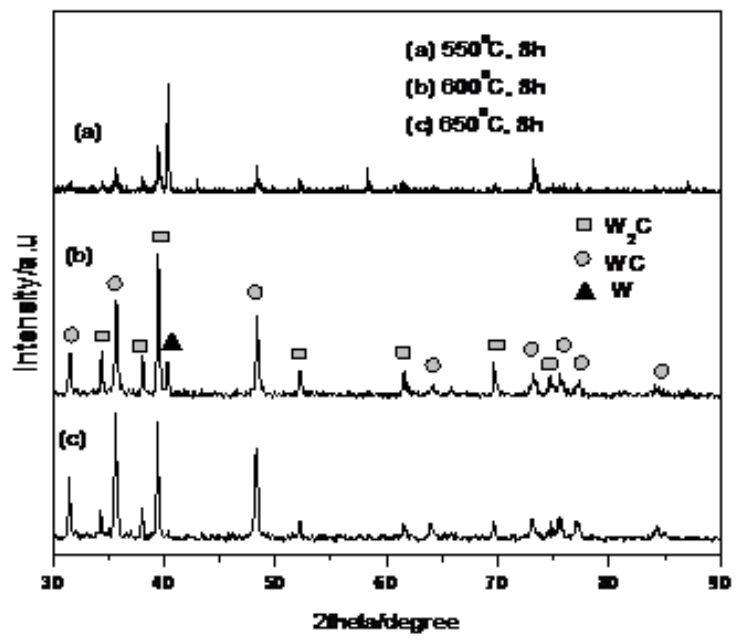

Fig.2 XRD patterns of the as-prepared samples under different conditions: (a) $550{ }^{\circ} \mathrm{C}, 8 \mathrm{~h}$; (b) $600^{\circ} \mathrm{C}, 8 \mathrm{~h}$; (c) $650^{\circ} \mathrm{C}, 8 \mathrm{~h}$

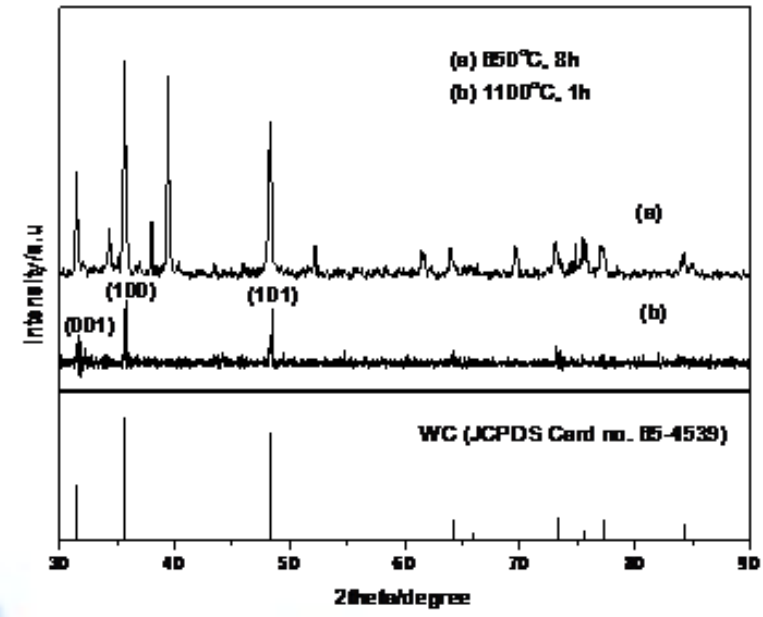

Fig.3 XRD patterns of the as-prepared samples under different conditions and WC (JCPDS Card no. 654539): (a) $650^{\circ} \mathrm{C}, 8 \mathrm{~h}$; (b) $1100^{\circ} \mathrm{C}, 1 \mathrm{~h}$

Fig. 3(a) shows the XRD pattern of the sample prepared at $650{ }^{\circ} \mathrm{C}$ for $8.0 \mathrm{~h}$. Fig.3 (b) shows the XRD pattern of the sample $\left(650{ }^{\circ} \mathrm{C}\right.$ and $8.0 \mathrm{~h}$ ), which is calcined in the molten salt at $1100{ }^{\circ} \mathrm{C}$ for $1.0 \mathrm{~h}$. From Fig. 3 (b), it is obvious that there is no W2C but WC. There are three obvious diffraction peaks in these patterns and all these diffraction peaks $\left(\begin{array}{llll}0 & 0 & 1\end{array}\right),\left(\begin{array}{ll}1 & 0\end{array}\right.$ $\left.0),\left(\begin{array}{lll}1 & 0 & 1\end{array}\right)\right)$ at different $d$-space can be indexed as hexagonal WC. The refinement gives the cell constants $a=2.90148 \AA$, $\mathrm{b}=2.90148 \AA$ and $\mathrm{c}=2.83028 \AA$, which are consistent with the value reported in the literature $(\mathrm{a}=2.902 \AA, \mathrm{b}=2.902 \AA$ and $\mathrm{C}=2.838 \AA$ ) (JCPDS card no. 65-4539). No evidences of impurities such as other tungsten carbides can be found in these $\mathrm{XRD}$ patterns. It is clear that $\mathrm{W}_{2} \mathrm{C}$ transforms to $\mathrm{WC}$ completely and the molten salt may protect the reactants against oxidation in air during calcining.

Fig. 4(a) and (b) show SEM images of as-prepared samples, which are prepared at the temperature of $600{ }^{\circ} \mathrm{C}$ and $650{ }^{\circ} \mathrm{C}$ for $8.0 \mathrm{~h}$, respectively. Fig. 4(c) shows SEM image of as-prepared sample $\left(650{ }^{\circ} \mathrm{C}\right.$ and $\left.8.0 \mathrm{~h}\right)$ calcined at $1100{ }^{\circ} \mathrm{C}$ for $1.0 \mathrm{~h}$ in the molten salt. According to the correspond XRD data, the sample of Fig.4 (a) is composed of W, WC and $\mathrm{W}_{2} \mathrm{C}$, the sample of Fig. 4 (b) is composed of WC and $W_{2} C$, and the sample of Fig. 4(c) is composed of WC only. Fig. 4(a) SEM image is not like Fig. 4(b) and (c); this is because the sample contains W powders. The morphologies of Fig. 4(b) and (c) look very similar. There is no obvious difference of morphology of $\mathrm{W}_{2} \mathrm{C}$ to WC. As mentioned above, WC was transformed from $W_{2} C$. That's why the morphologies of $W C$ and $W_{2} C$ are very similar. It is evident that the sample was composed of particles with a diameter of $200-400 \mathrm{~nm}$. However, particle aggregation seems to be severe.

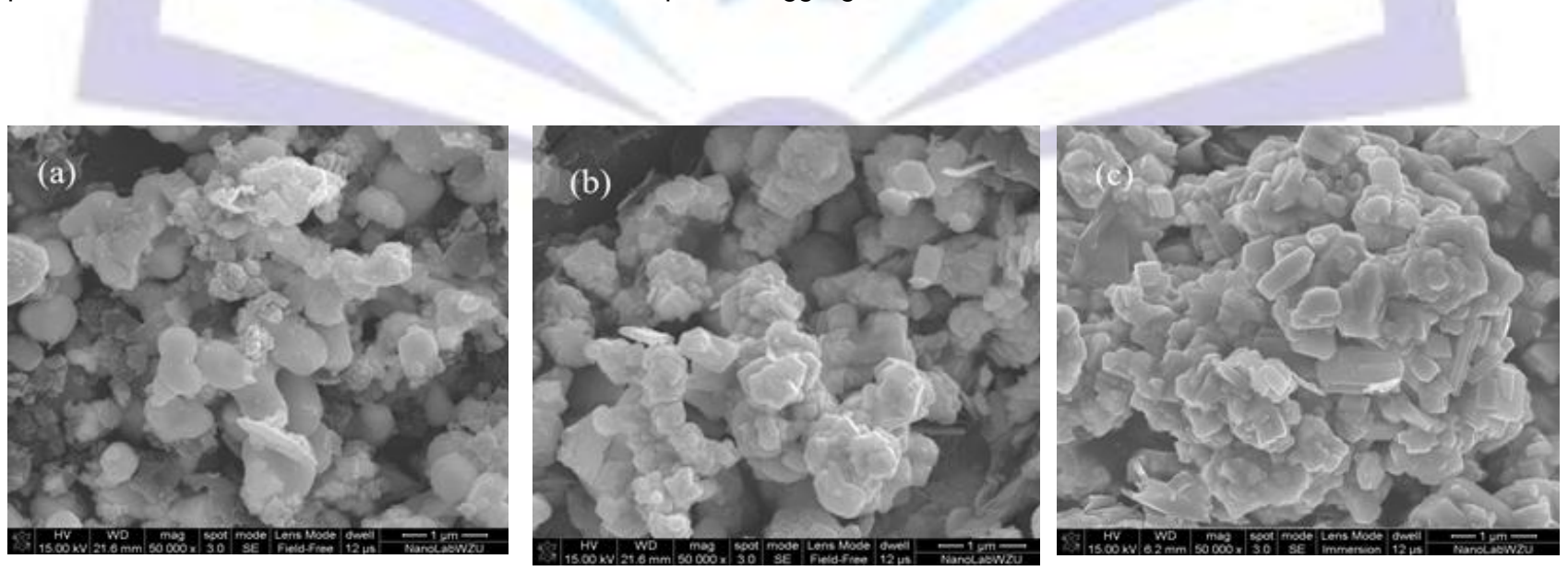

Fig.4 SEM images of the as-prepared samples were prepared under the different reaction temperatures and time

We also investigated the thermal stability of the WC powders in air under different temperatures. The thermal stability and the oxidation resistance of the WC powders were carried out below $1000^{\circ} \mathrm{C}$ under the flowing air by TGA, shown in Fig. 5 . 
From the TGA curve, we can find that the weight gain of the sample has not changed significantly below $550{ }^{\circ} \mathrm{C}$. A slight weight loss indicates that this maybe arise from the evaporation of absorbed water on the surface of the sample. But the quantity of the adsorbed water is very small. In this stage, the sample is very stable and do not start to oxidize. The beginning of the oxidation of the WC sample was found at $550{ }^{\circ} \mathrm{C}$, which indicates that the sample is oxidized by oxygen to form tungsten trioxide [29] and carbon dioxide. As the temperature rises, the amount of the formed tungsten trioxide becomes bigger, suggesting that the oxidation rate of the sample becomes faster. With temperature increasing to $750{ }^{\circ} \mathrm{C}$, the weight gain has no increase. From $750^{\circ} \mathrm{C}$ to $1000^{\circ} \mathrm{C}$, the weight gain remains almost constant on the TGA curve, indicating no weight change. The sample can be oxidized thoroughly at $750{ }^{\circ} \mathrm{C}$. But the sample has good thermal stability below $550^{\circ} \mathrm{C}$.

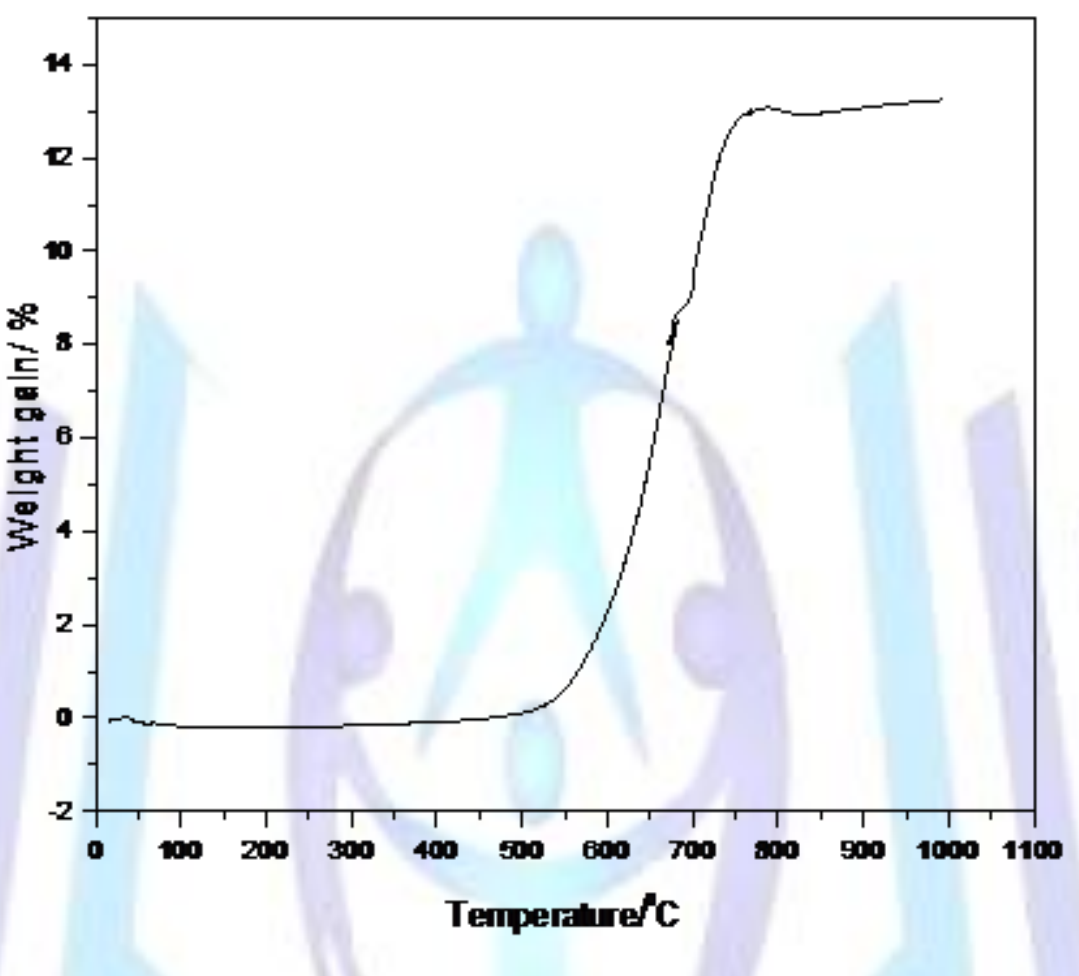

Fig. 5 TGA curve heated in flowing air for the WC sample

\section{Conclusion}

In this work, a novel two-step route to the synthesis route of ceramic powders has been presented. Firstly, $W C$ and $W_{2} C$ particles with a diameter in the range $200-400 \mathrm{~nm}$ were synthesized via a simple thermal route by the reaction of metallic magnesium powders with $\mathrm{WO}_{3}$ and oxalic acid in an autoclave at $650{ }^{\circ} \mathrm{C}$. Secondly, WC nanopowders were obtained by calcining the mixture of $\mathrm{WC}$ and $\mathrm{W}_{2} \mathrm{C}$ particles in the molten salt at $1100{ }^{\circ} \mathrm{C}$ for $1 \mathrm{~h}$. Moreover, the $\mathrm{W}_{2} \mathrm{C}$ will gradually transform to WC. The molten salt acts as a protecting media for the reaction. The WC sample had good thermal stability and oxidation resistance below $550{ }^{\circ} \mathrm{C}$. This simple chemical synthesis route of WC nanopowders may provide a general way to prepare other transition metal carbides.

\section{Acknowledgement}

This work was supported by Innovation and Promotion of science-technology project of Zhejiang Province, by Outstanding Person Foundation of Zhejiang Jiahe Plastic Co., Ltd and by Department of Education of Zhejiang Province of China under Grant No. 20070546.

\section{References}

[1] Scussel HJ. Friction and Wear of Cemented Carbides. ASM International, ASM Handbook, 1992; 18: 795-800.

[2] Schwartzkopf P, Kieffer R. Refractory Hard Metals-Borides, Carbides, Nitrides, and Silicides. MacMillan Company, New York, 1953.

[3] Kosolapova TY. Carbides: Properties, Production, and Applications. New York: Plenum Press, 1971.

[4] Toth LE. Transition Metal Carbides and Nitrides. New York and London: Academic Press, 1971. 
[5] Hugh O. Pierson Handbook of Refractory Carbides and Nitrides. New York: William Andrew Press, 1996.

[6] Ledoux L, Provost M, Pastor H, Leclercq G. Catalytic properties of transition metal carbides: II. Activity of bulk mixed carbides of molybdenum and tungsten in hydrocarbon conversion. J Catal 1989; 117: 384-395.

[7] Garg D, Dyer PN, Mater. Res. Fall Meeting 1989.

[8] Ghaisas S. Diffusion barrier performance of pulsed laser deposited amorphous tungsten carbide films. J Appl Phys 1991; 70: 7626-7628.

[9] Leclercq L, Provost M, Pastor H, Grimblot G, Hardy AM, Gengembre L. Catalytic properties of transition metal carbides: I. Preparation and physical characterization of bulk mixed carbides of molybdenum and tungsten. $\mathrm{J}$ Catal 1989; 117: 371-383.

[10] Ledoux MJ, Pham CH, Guille J, Dunlop H. Compared activities of platinum and high specific surface area $\mathrm{Mo}_{2} \mathrm{C}$ and WC catalysts for reforming reactions: I. Catalyst activation and stabilization: Reaction of n-hexane. J Catal 1992; 134: 383-398.

[11] Volpe L, Boudart M. Compounds of molybdenum and tungsten with high specific surface area: II. Carbides. J Solid State Chem 1985; 59: 348-356.

[12] Yih SWH, Wang CT. Tungsten: Sources, Metallurgy, Properties, and Applications. New York: Plenum Press; 1979. 385.

[13] Schubert WD, Neumeister H, Kinger G. Hardness to toughness relationship of fine-grained WC-Co hardmetals. Int J Refract Met Hard Mater 1998; 16: 133-142.

[14] Kim JC, Kim BK. Synthesis of nanosized tungsten carbide powder by the chemical vapor condensation process. Scripta Mater 2004; 50: 969-572.

[15] Jin YZ, Liu DL, Li XY, Yang RS. Synthesis of WC nanopowders from novel precursors. Int J Refract Met Hard Mater 2011; 29: 372-375.

[16] Wei CB, Song XY, Zhao SX, Zhang L, Liu WB. In-situ synthesis of WC-Co composite powder and densification by sinter-HIP. Int J Refract Met Hard Mater 2011; 28: 567-571.

[17] Cetinkaya S, Eroglu S. Comparative kinetic and structural analyses of nanocrystalline WC powder synthesis from prereduced $\mathrm{W}$ under pure and diluted $\mathrm{CH}_{4}$ atmospheres. Int J Refract Met Hard Mater 2011; 29: 214-220.

[18] Pallone EMJA, Martin DR, Tomasi R, Filho WJB. $\mathrm{Al}_{2} \mathrm{O}_{3}-\mathrm{WC}$ synthesis by high-energy reactive milling. Mater Sci Eng A 2007; 464: 47-51.

[19] Zawrah MF. Synthesis and characterization of WC-Co nanocomposites by novel chemical method. Ceram Int 2007; 33: 155-161.

[20] Bolokang S, Banganayi C, Phasha M. Effect of $C$ and milling parameters on the synthesis of WC powders by mechanical alloying. Int J Refract Met Hard Mater 2010; 28: 211-216.

[21] Essaki K, Rees EJ, Burstein GT. Influence of precursor preparation on the synthesis of WC under microwave irradiation. Mater Lett 2009; 63: 2185-2187.

[22] Liu WB, Song XY, Wang K, Zhang JX, Zhang GZ, Liu XM. A novel rapid route for synthesizing WC-Co bulk by in situ reactions in spark plasma sintering. Mater Sci Eng A 2009; 499: 476-481.

[23] Zellner MB, Chen JB. Synthesis, characterization and surface reactivity of tungsten carbide (WC) PVD films. Surf Sci 2004; 569: 89-98.

[24] Kumar A, Singh K, Pandey OP. Reduction of $\mathrm{WO}_{3}$ to nano-WC by thermo-chemical reaction route. Physica $\mathrm{E} 2009$; 41: 677-684.

[25] Kumar A, Singh K, Pandey OP. Optimization of processing parameters for the synthesis of tungsten carbide (WC) nanoparticles through solvo thermal route. Physica E: Low-dimensional Systems and Nanostructures 2010; 42: 2477-2483.

[26] Kumar A, Singh K, Pandey OP. Sintering behavior of nanostructured WC-Co composite. Ceramics International 2011; 37: 1415-1422.

[27] Kumar A, Singh K, Pandey OP. Direct conversion of wolframite ore to tungsten carbide nano particles. International Journal of Refractory Metals and Hard Materials 2011; 29: 555-558.

[28] El-Eskandarany MS, Mahday AA, Ahmed HA, Amer AH. Synthesis and characterizations of ball-milled nanocrystalline WC and nanocomposite WC-Co powders and subsequent consolidations. J Alloys Compds 2000; 312: 315-325.

[29] Warren A, Nylund A, Olefjord I. Oxidation of Tungsten and Tungsten Carbide in Dry and Humid Atmospheres. Int $J$ Refract Met Hard Mater 1996; 14: 345-353. 